\title{
Dos Seguros Supostamente Garantidos por Seguradores Estrangeiros Sem Operação Regular no Brasil Fraude a Consumidores e a Segurados em Geral
}

\section{Pedro Baumgarten Cirne Lima*}

\section{I- INTRODUÇÃ̃}

O objetivo desse pequeno estudo é alertar aos contratantes de seguros privados em geral, sejam pessoas físicas ou juridicas, sobre as conseqüências de fraudes que vêm sendo perpetradas no mercado nacional de seguros privados, em especial nos chamados ranos elementares, com a comercialização de seguros supostamente contratados com seguradoras sediadas em outros países, não constituídas como Sociedades Seguradoras no Brasil e, por conseguinte, sem autorização para aqui exercer suas atividades.

Tais "seguros", geralmente oferecidos por pseudo-representantes com a suposta chancela de grandes seguradores internacionais, por serem bastante mais baratos que os similares nacionais (o que, mais tarde, se verificará decorrer dá inexistência de custos, já que seguro não existe, pois o segurador referido no contrato, além de não estar autorizado a atuar no Brasil, não o assina, tendo seu nome indevidamente utilizado) despertam a atenção de pessoas físicas e jurídicas que, premidas pela necessidade cada vez maior de controle de custos, enxergam neles uma boa alternativa para manter seu patrimônio, ou o de terceiros que eventualmente lhes é confiado, garantido contra sinistros, a um custo mais baixo do que o habitualmente ofertado.

As respostas dadas pelos ofertantes desses seguros, quando confrontados com a inevitável pergunta, "Mas o seguro é válido, mesmo não tendo a seguradora autorização para

Advogado, Especialista em Direito da Empresa e da Economia pela Escola de Economia da Fundação Getúlio Vargas, lespecializando em Direito Internacional pelo Programa de Pós-Graduação da Faculdade de Direito da UFRGS. 
atuar no mercado brasileiro?", são as mais criativas. Vâo desde confusas explicações envolvendo regras das operações de resseguro, pouco conhecidas pelos leigos, passando pela suposta desnecessidade de autorização a partir do processo de desregulamentação do setor iniciado em 1992, chcgando inclusive à apresentação de interessantes teses jurídicas, teses essas que, todavia, não vêm acompanhadas da necessária chancela do Poder Judiciátio a amparar uma contratação proibida por lei (como se verá a seguir, para ser autorizada a operar como seguradora no Brasil, a empresa necessita de autorização concedida através de Portaria do Ministro da Indústria e do Comércio).

Todavia, esses contratos acabam por se revelar lamentáveis fraudes, geralmente bem elaboradas, com a apresentação de um contrato padrão, similar aos contratos de seguros brasileiros, acompanhados das condições gerais, sem que, entretanto, o suposto "garantidor" do seguro (normalmente alguma conhecida seguradora européia ou norteamericana sem atuação no Brasil), tenha qualquer participação ou mesmo conhecimento do contrato nem, conseqüentemente, qualquer responsabilidade sobre a "apólice" vendida ao lesado contratante.

Para evitar a ocortência de tais fraudes, a mera observância da lei já seria suficiente, pois, ao se deparar com una "tentadora" oferta similar à acima descrita, basta ao interessado, seja ele pessoa física ou jurídica, atentar para o que determinam os diplomas legais que disciplinam o funcionamento dos seguros privados no Brasil. O exame da proposta de scguros à luz dos ditames legais, principalmente no que diz respeito à capacidade da companhia seguradora que a subscreve para operar como tal, pode evitar os pesados dissabores advindos da contratação de um seguto "fantasma".

Entretanto, em muitas oportunidades, ral cuidado é posto de lado, levando à efetiva contratação, que, por ocasião da efetivação de eventual sinistro, acaba por deixar o segurado sem a cobertura contratada.

Nas linhas a seguir traçadas, busca-se ressaltar, através de uma análise do ponto de vista juridico, a importância do criterioso exame, pelo interessado, da proposta de seguro que the é apresentada, bem como sugerir alternativas possíveis na defesa de seus interesses, na hipótese de efetiva assinatura de tal espécie de contrato e da verificação de sinistro.

\section{II - DA ORIGEM DO CONTRATO DE SEGURO EDAS COMPANHIAS SEGURADORAS}

Segundo a melhor doutrina, na Antiguidade não se conheceu o contrato de seguro, o qual teria surgido no final da Idade Média, a partir da necessidade de maior segurança para aqueles negociantes que faziam investimentos de vulto no crescente transporte marítimo de mercadorias.

Admite Pedro Alvim que existiam, na idade antiga, institutos próximos ao do seguro, como as sociedades de socorro mútuo surgidas na Ásia e desenvolvidas pelos gregos, 
sob o nome de sinedrias, betarios ou beranos, e igualmente em Roma, onde eram conhecidas como sodalitia ou collegia.'

Compartilham dessa opinião, entre outros, Silvio de Salvo Venosa ${ }^{2}$ e Pontes de Miranda que, em seu "Tratado de Direito Privado", afirma que o direito tomano ignorou o contrato de seguro, que teve origem no transporte por mar e, embora refira que, na Idade Média, havia institutos parecidos, mas não idênticos ao seguro, em momento posterior, faz referência à existência de apólices de seguro naquele período histórico. ${ }^{3}$

As primeiras apólices de seguro conhecidas, segundo Alvim, são uma de Pisa, datada de 11 de julho de 1385, e outra de Florença, datada de 10 de julho de 1397. A partir de então, o seguro teria obtido impulso considerável, com a crescente assinatura de contratos, surgindo no século XV, nas Ordenanças de Barcelona, em 1435, as primeiras disposições legais relativas a tal espécie de contrato, com a criação de um tribunal especializado para julgamento da matéria. ${ }^{4}$

Inicialmente, os seguradores eram comerciantes que se reuniam em grupos, garantindo as operações de transporte matítimo das quais participavam contra os infortúnios tão comuns naquela época e que poderiam, na ausência de tal espécie de garantia, levá-los à insolvência.

1 "A forma primitiva em que se pode filiar a idéia rudinentar de seguro - escreve Fernando Emygidio da Silva - confunde-se com o socorro mútuo, no seu sentilo mais amplo e duma organização de pessoas que se prestem reciprocamente serviços por meio de um fundo comum de qualquer maneira constituído.

A história registra a existência dessas sociedades desde renota antigüidade. Segundo Plínio, funcionavam na Asia ad sustinendam tenuiorum inopiam. Esclarece o citado autor Ferrando Emygidio da Silva que os gregos detam um largo desenvolvimento ao principio associativo em todas as suas formas, religiosa, politica, comercial, maritima - e como tal criaram, sob o nome de sinedrias, hetarios ou heranos, sociedades do tipo do socorto muturo. (...)

Aparecen também en Roma, sob a denominação de sodalitia ou collegia." (O Contrato de Seguro, $3^{2}$ ed. Rio de Janeiro: Forense, 1999, pág. 3)

2 "O seguro surge inicialmente no direito marítimo da ladade Média. Embora possuísse institutos próximos, a Antiguidade tã̃o conheceu este contrato." (Direito Civil, $4^{*}$ ed. São Paulo: Adas, 2004, vol. 3, pág. 384)

3 "4. FONTES DO DIREITO DE SEGURO - O direito romano ignorou o contrato de seguro.

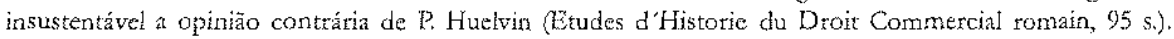
$\mathrm{Na}$ İlade Média, há instrututos parecidos, porém não icênticos, quais os pactos de comunhão de danos sofridos pelos cidadãos, se se desconheciam os causadores, e os vinculos entre membros da mesma ou diferentes corporaçöes metcantis (cf. F. Schupfer, I II Diritto dell' Obbligazioni in Itália nell' Età del Risorgimento, 211-261). Se setnethanças com o mútuo a risco levou a pensar-se em que nesse estivesse a origem do contrato de seguto, por ser a prestação do mutuário "seguro antecipado" (LEVIN GOLDSCHMIDT); mas é forçada a afrmação de continuidade histórica. O transporte por mar criou o contrato de seguro.(...)

A apólice de seguro, já na Kade Média teve parata executio e prompta executó "(Tratado de Direito Privado: direito das obrigações, $2^{n}$ ed. Rio de Janeiro: Borsoi, 1964, tomo XLV, págs. 277/278).

4 Ob. cit., pág. 28. 
Pontes de Miranda faz referência ao início da sucessão desses grupos de seguradores, os seguradores em comum, pelas empresas seguradoras já no século XVII. ${ }^{5}$

Alvim afirma que, com o avanço das transações comerciais, a figura do segurador individual, pelas mais diversas razões (dentre as quais a falta de condições de uma pessoa individualmente estruturar técnica e econotnicamente um empreendimento de seguros), foi perdendo aceitação, passando a doutrina a admitir de forma unânime, ptincipalmente em razão do esforço de Vivante neste sentido, que o seguro deve set explorado como atividade empresarial ${ }^{6}$, como de fato vem sendo explorado atualmente, estando a possibilidade de operação de seguradores individuais hoje limitada à Inglaterra, onde se reúnem sob o pálio do Lloyd's of London, organização tradicional e que ainda goza de prestígio em todo o mundo.

\section{III - QUEM PODE ATUAR COMO SEGURADOR NO MERCADO BRASILEIRO}

Durante muito tempo, as leis que regulavam a contratação de seguros não se preocuparam em criar restrições à capacidade dos contratantes, podendo quálquer pessoa, física ou jurídica, desde que dotada dos recursos necessários e contando com segurados interessados, atuar como segurador.

Embora, segundo Pedro Alvim, não se tenha notícia da operação no Brasil, em caráter esporádico e regular, de seguradores individuais, tendo o seguro surgido em nosso país já através da figura da sociedade seguradora ${ }^{7}$, a priori, qualquer pessoa, física ou jurídica, com capacidade para assumir obrigações poderia firmat um contrato de seguro na posição de segurador.

Aliás, a leitura do Código Civil Btasileiro vigente até 10 de janeiro de 2003, Lei n ${ }^{\circ} 3.071$, de $1^{\circ}$ de janeiro de 1916 , por certo induziria a esse raciocínio, uma vez que seu artigo 1.432 ,

" "As companhias de segruto sucederam aos seguradotes em conum, co-seguradores, mas já no século XVII." (GIOVANI CASSANDRO, Assicutazione [storia], Ėnciclopedia del Diritto, III, 426). Ob. cit, Tomo XVL, pág. 278.

" "Coube a Vivante o mérito de iniciar a luta contra os seguradores individuais, mostrando que se trata de uma atividade que não comporta as operações isoladas ou eventuais. Só a empresa de seguros com suporte económico e técnico e um trabalho permanente pode consolidar suas operaçōes e oferecer garantia a seus segurados" (ob. cit., pág. 179)

" "Não há notícia de ter operado ern nosso país algum segurador individual, explorando essa atividade ern caráter esporádico ou tegular... (...)

A primeira seguradora, criada en princípios de 1808 , na Bahia, já surgiu sob a forma empresarial, como sociedade de capital. Outras se consțituíram pelo mesmo processo, sob a tutela da legislação comuin sobre sociedades anônimas." (ob. cit., págs. 183/184). 
inserido na seção I do Capítulo XV, que trata das disposições gerais do Contrato de Seguro, definia como sendo o contrato de seguro "aquele pelo qual uma das partes se obriga para com a outra, mediante a paga de um prêmio, a indenizá-la do prejuízo resultante de risscos futuros, previstos no contrato." 8

Todavia, não é esta a realidade pois, por força do Sistema Nacional de Seguros Privados (seguros privados englobam os seguros de coisas, pessoas, bens, responsabilidades, obrigações, direitos e garantias), criado attavés do Decreto-Lei $n^{\circ} 73$, de 21 de novembro de 1966 e regulamentado pelo Decreto $n^{\circ} 60.459$, de 13 de março de 1967, estão estabelecidos quais tipos de pessoas jurídicas podem realizar operaçōes de seguro no Brasil e mediante que condições.

No artigo 24 do DI. 73/66, está estabelecido que somente as Sociedades Anônimas ou Cooperativas, devidamente autorizadas, poden operar em seguros privados, sendo que, às últimas, é possivel apenas atuar em seguros agrícolas, de saúde e acidentes do trabalho."

A respeito da atuação das cooperativas, importante considerar a observação de Waldírio Bulgarelli, de que estão impedidas de atuar por falta de regulamentação do DL 73/66 na parte relativa a elas ${ }^{10}$, o que explica a correção da afirmação de que apenas as sociedades anônimas podem atuar como seguradoras no mercado brasileiro.

Portanto, nos termos Decreto-Lei $n^{\circ} 73 / 66$, que cria o Sistema Nacional de Seguros Privados e estabelece suas diretrizes, e do Decreto $n^{\circ} 60.459 / 67$, que o regulamenta, com a ressalva feita às Cooperativas, na prática, somente as Sociedades Anônimas devidamente autorizadas pela autoridade estatal podem atuar como seguradores. E essa autorização, segundo determina o art. 74 do DL 73/66, é concedida pelo Ministro da Indústria e Cométcio, através de Portaria, a partir de requeximento dos incorporadores, dirigido ao CNSP (Conselho Nacional de Seguros Privados) e apresentado pela SUSEP (Superintendência Nacional de Seguros Privados). ${ }^{11}$

- "Art. 1.432. Considera-se contrato de seguro aquele pelo qual uma das partes se obriga para com a outra, mediante a paga de um prêmio, a indenizála do prejuizo resultante de riscos futuros, previstos no contrato."

9 "Art. 24. Poderão operar em seguros privados somente Sociedades Anônimas ou Cooperativas, devidamente autorizadas.

Parágrafo único. As Sociedades Cooperativas operatão unicamente em seguros agrícolas, de saúde e de acidentes do trabalko."

to "No Brasil, adotou-se, com o Decreto-lei $\mathrm{n}^{\circ} 73$, de 21 de novembro de 1996, um sistema de seguros (...) , permitindo-se que atuem, como seguradores, apenas sociedades anônimas (e com tipo especírco, capital, açôes etc. regulamentados) e cooperativas (estas, porén, até hoje impedidas de atuar no campo dos seguros, por terem os responsáveis oficiais esquecido de regulamentar o Decreto $7^{\circ} 73$, na parte referente a elas)." (Contratos Mercantis, $10^{2}$ ed. São Paulo: Atlas, 1998, pág. 638)

11 "Art. 74. A autorizaçâo para funcionamento será concedida através de Portaria do Miristro da Indústria e do Comércio, mediante requerimento firmado pelos incorporadores, dirigido ao CNSP e apresentado por intermédio da SUSEP". 
No mesmo sentido, o atual Código Civil Brasilleiro, Lei n ${ }^{\circ}$ 10.406/02, deixa claro que existem restrições à capacidade do segurador, pois, embora o caput do art. 757 , praticamente repita os termos do artigo $1.432 \mathrm{da}$ lei civil anterior, ao definir o contrato de seguro como aquele pelo qual "o segurador se obriga, mediantepagamento do prêmio, a garantirinteresselegítimo do segurado, relativo a pessod ou coisa, contra riscos predeterminados", referido artigo prevê, no seu parágrafo único, que somente poderá contratar como segurador "entidade para tal fim legalmente autorizada."

\section{IV - DAS EXIGÊNCIAS IMPOSTAS AO SEGURADOR PELO SISTEMA NACIONAL DESEGUROS PRIVADOS}

Em relação aos seguradores, o anteriormente mencionado Sistema Nacional de Seguros Privados estabelece uma série de exigências, as quais se mostram totalmente pertinentes para assegurar o cumprimento das obrigações contratadas com os segurados na hipótese de verificação de sinistros, garantindo a estabilidade e confiabilidade do sistema.

Em primeiro lugar, cabe-nos elencar, de forma genérica, quais as principais exigências que a legislação brasileira estabelece para reconhecer a capacidade de uma empresa para atuar como companhia seguradora no país e autorizar-lhe o funcionamento como tal.

Esses requisitos legais estão fixados no Decreto-Lei ${ }^{\circ} 73 / 66$, regulamentado pelo Decreto n $60.459 / 67$, que "dispõe sobre o Sistema Nacional de Seguros Privados, regula as operações de seguros e resseguros e dá outras providências".

Em seu Capítulo VII, o DL 73/66 trata “Das Sociedades Seguradoras", estabelecendo, no artigo 72 , que serão regula das pela legislação geral, no que for aplicável, e especialmente pelas disposições do Decreto-Lei.

No artigo seguinte (73), o texto legal estabelece que as seguradoras não poderão explorar qualquer outro ramo de comércio ou indústria, limitando suas atividades às de operação em seguros privados.

A Seção II (artigos 74 a 76) do Capitulo VII do DL 73/66 e a Seção I (artigos 42 a 47) do Capítulo VI do Dec. 60.459/67 tratam da autorização para funcionamento das companhias seguradoras, que será concedida através de através de Portaria do Ministro da Indústria e Comércio.

12 "Art. 757. Pelo contrato de seguto, o segurador se obriga, mediante o pagamento do prêmio, a garantjr interesse legítimo do segurado, relativo a pessoa ou coisa, contra riscos predaterminados.

Parágrafo único. Somente pode ser parte, no contrato de seguro, como segurador, entidade para tal fim legalmente autorizada." 
Inicialmente, os incorporadores devem apresentar, via SUSEP (Superintendência de Seguros Privados), requerimento ao CNSP (Conselho Nacional de Seguros Privados), instrúdo com prova da regularidade da constituição da Sociedade, depósito perante o Banco do Brasil da parte do capital já realizada e cópia do estatuto social.

O pedido de autorização é submetido, pela SUSEP, à apreciação pelo CNSP que, após analisá-lo frente aos critérios estabelecidos nas alíneas "a" a "f" do art. 43 do Dec. $60.459 / 67$ (dentre os quais podemos destacar a saturação e a possibilidade do mercado segurador nacional, a probabilidade de êxito de suas operações e a regularidade de constituição da sociedade), opinará sobre a concessão ou não do requerimento.

Publicada a Portaria de autorização de funcionamento e comprovados, perante a SUSEP, a subscrição de ações do Capital do IRB (Instituto de Ressegutos do Brasil), a efetivação de todos os registros e publicação de atos exigidos por lei para seu funcionamento, a satisfação das exigências eventualmente constantes da Portaria de Autorização e o cumprimento das exigências suplementares estabelecidas pela SUSEP (art. 45 do Dec. 60.459/ 67), será expedida pelo Ministro da Indústria e do Comércio, tal como ocorre com as instituições financeiras, uma Carta Patente para funcionamento da Sociedade. Este documento, uma vez registrado na SUSEP, arquivado no órgão do Registro do Comércio da sede da Sociedade e tendo publicada sua certidão de arquivamento no "Diário Oficial" da União, desde que preenchidas as demais exigências legais, dará direito ao início das operações da seguradora (art. 46 do Dec, 60.459/67).

Importante ainda ressaltar que, nos termos do art. 78 do DL 73/66, a Seguradora somente poderá operar nos seguros para os quais especificamente possua autorização, de acordo com os planos, tarifas e normas aprovadas pelo CNSP.

Nos termos do artigo 48 do Dec. 60.459/67, o CNSP estabelece um capital inicial mínimo para operação nos seguros de direitos, coisas, obrigações e bens, além de capitais adicionais para atuação em seguros de responsabilidades, de garantia, de acidentes pessoais, de saúde e de pessoas. Referidos capitais devem sofrer atualização pelo CNSP com periodicidade mínima de dois anos, nos termos do $\$ 2^{\circ}$ do mencionado art. 48 .

Em razão de não haver sido regulamentada a Lei $n^{\circ} 5.627 / 70$, que determina a variação dos capitais mínimos para cada ramo, de acordo com as regiões geográficas do país, vige a decisão do CNSP, segundo a qual os capitais mínimos são fixados para seguros de dois grandes grupos, os de ramos elementares e os de vida. Atualmente (junho de 2004), o capital mínimo exigido de uma seguradora de atuação nacional, para operação nos seguros de ramos elementares, segundo informação da SUSEP, não poderá ser inferior a $\mathrm{R} \$$ $7.200,000,00$ (sete milhões e duzentos mil reais).

Exige ainda o DL 73/66, em seu arr. 84, como medida para garantir o atendimento, pelas Sociedades Seguradoras, das obtigações por elas assumidas, a constituição de reservas técnicas, fundos especiais e provisões, dentro de critérios estabelecidos pelo CNSP, assim como reservas e fundos dererminados em leis especiais. 
A destacar ainda o artigo 63 do Decreto regulamentador do sistema, que impõe às Sociedades Seguradoras o dever de dat publicidade a seus atos, obrigando-as a publicar anualmente seus balanços, contas de lucros e perdas e pareceres dos respectivos Conselhos Fiscais, a tealizar anualmente sua Assembléia Getal Ordinária e a enviar a ata à SUSEP, juntamente com as atas das demais Assembléias Gerais eventualmente realizadas, bem como a manter, na matriz e nas sucursais, a escrituração completa das operações efetuadas.

Tais exigências demonstram a preocupação do legislador brasileiro em dotar o sistema nacional de seguros pivados de mecanismos capazes de controlar a regularidade de constituição das Sociedades Seguradoras e de seu funcionamento e a capacidade dessas empresas de honrar os riscos segurados, bem como em possibilitar a identificação e responsabilização dos administradores por irregularidades ou ilegalidades eventualmente promovidas.

\section{V - DA IMPORTÂNCIA DA FISCALIZAÇÃO E DO CONTROLE DO SISTEMA NACIONAL DE SEGUROS PRIVADOS PELA SUSEP}

Diante das colocações acima expendidas, resta patente a importância, para o mercado segurador brasileiro, do Sistema Nacional de Seguros Privados, cuja composição e funcionamento estão disciplinados basicamente pelo Decreto-Lei $n^{\circ} 73 / 66$, regulamentado pelo Decreto ${ }^{\circ} 60.459 / 67$, não se tratando sua existência de mero apego ao formalismo legal ou de burocracia estatal criada para gerar empregos ou dificultar a efetivação dos contratos de seguro.

Apenas para demonstrat a importância da fiscalização estatal sobre a atividade securitária, no início do século XX, Clóvis Beviláqua já fazia menção a respeito, tratando o tema como "face importante do sistema de seguros."

Feito esse pequeno parêntese histórico, retornemos ao Sistema Nacional, que é composto por três órgãos oficiais, o Conselho Nacional de Seguros Privados (CNSP), a Superintendência de Seguros Privados (SUSEP) e o Instituro de Resseguros do Brasil (RRB), cada um com sua função específica, além das Sociedades Seguradoras autorizadas e dos corretores habilitados, e disciplina as operações de seguros privados no país. Através dos supra mencionados textos legais, define direitos e obrigações de cada um dos seus participantes,

13 "II. Uma face importante do problema dos seguros, relativamente cedo, despertou a attenção do nosso legislador: a fiscalização das socjedades de seguro por parte do governo, e a sua organização obedecendo às normas garantidoras dos interesses particulares confiados às mesmas. (1)"

$\cdots$

(1) Vejam-se Relatorios do inspector de seguros, Dr. Verne Abreu, em 1906 e 1908. (Direito das Obrigaçṑes, Campinas: Red Livros, 2000, pág. 496) 
estabelece formas de controle e penalidades para quem descumprir as determinações legais, o que possibilita o regular funcionamento do mercado e, em última análise, busca evitar a ocorrencia de prejuizos aos segurados, esses entendidos como as pessoas físicas ou jurídicas que buscam garantir seu patrimônio, ou o patrimônio de terceiros, contra os mais diversos riscos, tais como furtos, roubos, acidentes, extravios, intempéries, etc.

O papel da SUSEP, nos termos do disposto nos artigos 36 do DL 73/66 e 33 do Dec. $60.459 / 67$, é o de executora da políica de seguros estabelecida pelo CNSP (que, por sua vez, é o órgão consultivo, organizador do Sistema Nacional de Seguros) cabendo-lhe a fiscalização da constituição, organização, funcionamento e operações das Sociedades Seguradoras.

Sendo assim, cabe à SUSEP, a quem a lei não apenas dá poder, mas estabelece o dever de fiscalizar as operações de seguro no país, coibir quaisquer irtegularidades ou ilegalidades verificadas no mercado segurador, inclusive eventuais operaçōes de seguros ilegais, contratadas por falsos representantes de empresas que não têm autorização para funcionar, no Brasil, como Seguradoras.

Em outros paises, onde semelhante sistema de controle estatal existe, a importância da atuação do ente executor da política estatal de seguros na fiscalização do mercado de seguros privados é igualmente reconhecida. O prof. Carlos Alberto Ghersi na obra intitulada "Contratos civiles y comerciales" ressalta a responsabilidade da Superintendencia de Seguros de lá Nacion, órgão estatal argentino similar à SUSEP brasileira, nos termos da lei daquele país, afirmando que o Estado assume a obrigação jutídica de garantia, consistente em assegurato correto funcionamento do sisterna de seguros, para garantir aos segurados a efetiva reparação dos danos sofridos mesmo em caso de eventual insolvência do agente segurador. ${ }^{14}$

Como se vê, o papel do Estado enquanto ente fiscalizador dos mercados, particularmente do mercado de seguros privados, é tema relevante, merecedor de abordagens pelos doutrinadores nacionais e estrangeiros, exatamente pelo fato de que é obrigação do governo assegurar o correto funcionamento do Sistema Nacional de Seguros Privados.

14 "La ley 20.091 determina con claridad el sometirniento de la actividad aseguradora a su régimen y el control de la autoridad de la Superintendencia de Seguros en forma exclusiva y excluyente; su intervención no se limita a la autorización para opezar en seguros, sino que se prolonga durante toda la vida da la aseguradora mediante una efectiva fiscalización, para lo eual ésta debe adoptar todas las medidas adecuadas con el objeto de mantener la indemnidad de su patrimonio.

(...)

El Estado asume, por lo tanto, una obligación juridica de garantía que consiste en asegurar el correcto funcionamiento del servicio del sistema asegurativo, a fin de no frustrar la efectiva reparación de los damnificados ante una eventual insolvencia de la empresa aseguradora." (Contratos civiles y comerciales, $4^{a}$ ed. Buerios Aires: Astrea, 1999, págs. 479/480) 
Mas o reconhecidamente necessário controle oficial do mercado de seguros privados, em especial no que se refere às operações contratadas por falsos representantes de empresas que não são Sociedades Seguradoras autorizadas a atuar no Brasil, somente pode ser adequadamente exercido em sua plenitude se houver respeiro, pelos seguradores, corretores, estipulantes e demais agentes do mercado segurador, inclusive segurados, às regras estabelecidas para as operações de seguros privados, evitando a oferta e a contratação de seguros que não sejam firmados e gatantidos por seguradoras autorizadas. Em especial no que se refere à cometcialização, cada vez mais corrente, dessa espécie de contratos, supostamente garantidos por seguradoras estrangeiras, pessoas jurídicas sem qualquer espécie de registro junto à SUSEP e, conseqüentemente, sem autorização para atuar no mercado segurador brasileiro (muitas vezes, inclusive sem constituição regular no Brasil), pouco pode fazer a Superintendência quanto à preservação do patrimônio do segurado.

Estes contratos, não reconhecidos como operações de seguros pela lei brasileira, na maior parte das vezes (se não em todas), sequer têm a efetiva participação das seguradoras estrangeiras neles mencionadas como garantidoras do risco, sendo seus nomes indevidamente utilizados para perpetrar fraudes contra o consumidor brasileiro, fraudes essas cujos mentores não apresentam, via de regra, patrimônio suficiente para garantir o cumprimento das obrigações contratadas em casos de sinistro.

Eé aí que surge a dificuldade de atuação da SUSEP, na medida em que, embora exista punição prevista pelo CNSP para as hipóteses de pessoa física ou jurídica que realizar operações de seguro sem autorização, consistente em multa no valor igual ao da importância segurada (artigos $8^{\circ}$ e $9^{\circ} \mathrm{da}$ Resolução CNSP $n^{\circ} 60 / 01$ ), a pena, na prática, se revela inócua quando aplicada contra pessoas físicas ou jurídicas sem patrimônio algum, como é o caso da maioria daquelas que se avenruram a contratar seguros sem autorização para tanto.

Neste ponto se revela a importância do respeito ao sistema e ao controle estatal, via SUSEP, das operações e das seguradoras, na medida em que, se estivéssemos a tratar de ilegalidade cometida por seguradora regularmente constituída sob a forma de sociedade anônima e autorizada a atuar no Brasil, essa certamente teria reservas de capital suficientes para responder por seus atos, e seus dirigentes e acionistas, por certo, não teriam interesse em receber punições pecuniárias, temendo o abalo da marca da empresa junto ao mercado de seguros.

Já o mesmo não se pode dizer dos falsos seguradores, que por vezes sequer pessoa jurídica regularmente constituida representam, pouco thes importando a aplicação de multa pecuniária, pois não possuem bens capazes de pagá-la, tampouco o abalo da marca no mercado, pois geralmente se utilizam, de forma indevida, de marca alheia.

Daí que, no aspecto atinente à pteservação dos interesses daquele segurado que, de boa-fé, contrata seguro fraudulento, pouco podem fazer os integrantes do Sistema Nacional de Seguros Privados, cabendo ao próprio lesado buscar ressarcimento junto ao pretenso agente do segurador. 


\section{VI - DA NECESSÁRIA INTERVENÇÃO DO IRB NO REPASSE DE SEGUROS OURESSEGUROS AO EXTERIOR}

Segundo os termos do "caput" do art. 81 do Decreto-Lei n" $60.459 / 67$, qualquer operação de resseguro ou seguro no exterior é necessariamente efetuada attavés do IRB. ${ }^{15}$

Embora o monopólio do $\mathrm{RB}$ tenha sido relativizado com o início do processo de privatização do instituto, através da revogação do dispositivo legal acima transcrito pela Lei $n^{\circ}$ 9932/99, a eficácia dessa lei está suspensa por meio de medida liminar, concedida pelo Supremo Tribunal Federal nos autos das Açôes Diretas de Inconstitucionalidade $n^{\circ} \mathrm{s} 2244 \mathrm{e}$ 2223, que ainda pendem de julgamento definitivo ${ }^{16}$.

Surge, assim, mais um motivo para o questionamento, pelo segurado, quanto à validade do seguro, pois, se o risco, em parte ou integralmente, é repassado a empresa estrangeira, necessária se faria a intermediação do IRB, que não se faz presente nessas obscuras contratą̧ões.

\section{VII - DA NULIDADE DO CONTRATO E DA OBRIGAÇÃO DE INDENIZAR PELO ATO ILÍCITO.}

Frustrado o segurado na tentativa de receber o valor da indenização correspondente à cobertura pactuada, ao descobrir que o segurador não possui autorização para atuar como segurador no Brasil e que sequer firmou o contrato, mas sim seu alegado agente ${ }^{i 7}$, que, em verdade, não o representa, deve se voltar contra este último na defesa de seus interesses.

De início, salta aos olhos o inegável dolo contido no agir do firmatário do contrato, que se utiliza de artifício para induzir o segurado a praticar ato que vem em seu prejuizo e em favor do primeiro. Ao distinguir o dolo da lesão, Marcelo Guerra Martins, de maneira sintética e precisa, o define como "um erro provocado pela artimanha e má-fé de um dos contratantes". ${ }^{18}$

is "Art. 81. A colocação de seguro e resseguro no estrangeiro será feita exclusivamente por intermédio do IRB."

16 "A ADI 2223, proposta pelo PT (Partido dos Trabalhadores) teve a liminat concedida referendada pelo Pleno do TST em 10.12.02, decisào publicada no D.J e no D.O.U. em 05.12.03, estando arualmente com vista ao Advogado Geral da União e ADI 2244, proposta pelo PC do B (Pattido Comunista do Brasil), foi retirada de pauta em 19.12.03, decisão pulblicada no D.J e no D.O.U. cm 13.02.04."

17 "A referència a agente do segurador é extraída do art. 775 do CCB que, ao que parece, prevê o estabelecimento de contratos de agência, nos termos daqueles previstos nos artigos 710 a 721 do CCB, entre seguradoras e agentes autorizados a representánlas (os quais, na atual conformação do sistema nacional de seguros privados, seriam os corretores):

Art, 775. Os agentes autorizados do segurador presumern.se seus tepresentantes para todos os atos relativos aos contratos que agenciâtem."

: Lesão Contratual no Dircito Brasileiro, Riò de Janciro: Renovar, 2001, pág. 105. 
Diante da conduta dolosa daquele que assina o contrato como agente ou representante do segurador, somado ao fato de que se trata de negócio jurídico estabelecido entre particulares, poder-se-ia pensar na hipótese de ato anulável, pois assim o são aqueles praticados com vício resultante de dolo, segundo dispóe o art. 171 do $\mathrm{CCB} .{ }^{19}$

Todavia, nos parece que, diante das circunstâncias específicas, notadamente o interesse público envolvido no correto funcionamento do Sistema Nacional de Seguros Privados, o negócio juridico estabelecido entre os signatários do contrato seja nulo.

Enzo Roppo ensina que "o contrato é nulo quando a operação jurídico-econômica que deveria comesponder the, ounãopoderealizar-seou,podendoembora realizarse, éreprovadapelo ordenamento jurídico". 20"

Carlos Aberto da Mota Pinto estabelece as distinções entre as figuras da nulidade e da anulabilidade de maneira sucinta e elucidativa, esclarecendo que o negócio nulo, devido à falta ou ao vício de algum dos elementos internos ou formativos, desde o início não produz os efeitos esperados, e que o regime e os efeitos da nulidade são mais severos porque têm fundamento em motivos de interesse público; enquanto que o negócio anulável, igualmente contendo falta ou vício de elemento interno ou formativo, produz efeitos e é tratado como se válido fosse enquanto não for declarado inválido por decisão judicial, a partir da iniciativa de uma das partes, e seus efeitos não são tão severos quanto os da nulidade porque fundamse na infração de regras relativas à tutela dos interesses privados. ${ }^{21}$

Roppo estabelece, quanto às razões que fundamentam as hipóteses de nulidade e anulabilidade, as mesmas distinções entre o interesse público e o interesse privado referidas por Pinto. ${ }^{22}$

19 "Art. 171. Além dos casos expressamente declarados na lei, é anulável o Begócio jurídico:

I - por incapacidade relativa do agente;

If - por vicio resultante de erro, dolo, coação, estado de perigo, lesão ou fraude contra credores."

2v O Contrato, Tradução de Ana Coimbra e M. Januário C. Gomes, Coimbra: Livraria Almedina, 1988, pág. 195.

21 "O negócio nulo não produz, desde o início (ab iritio), por força da falta ou vício de um elemento intemo ou formativo, os efeitos a que tendia. O negócio anulável, não obstante a falta ou vicio de um elemento interno ou formativo, produz os seus efeitos e é tratado como válido, enquanto não for julgada procecente uma acção de anulação; exercido, mediante esta acção, o direito potestativo de anular, pertencente a uma das partes, os efeitos do negócio säo retroativamente destruídos.

$O$ regime e os efeitos mats severos da nulidade encontram o seu fundamento teleológico em motivos de interesse público predominante. As anulabilidades fundam-se na infracção de requisitos dirigidos à tutela de interesses predominantemente particulares." (Teoria Geral do Diteito Civil, Coimbra: Coimbra Editora, 1999, pág. 610)

22 "Enquanto a anulabilidade, como veremos, está geraimente disposta à tutela dos interesses particulates de uma das partes do contrato, em regra a lei comina a nulidade todas as vezes em que dar actuação ao negócio contraria exigências de carácter geral, on o interesse público." (Ob. cit., pág. 205). 
Essas lições, especialmente no que se refere ao envolvimento do interesse público, claramente presente na necessidade de que se tespeite a determinação legal de que somente seguradoras autorizadas por lei a atuar como tal contratem seguros, preservando assim o Sistema Nacional de Seguros Privados e garantindo efetividade à tarefa de fiscalização e aplicação de sanções que the incumbe, reforçam nosso entendimento no sentido de que a operação que ora se estuda seja nula, e não anulável.

Não se trata apenas da preservação do interesse dos contratantes diretamente envolvidos, mas do interesse público de que se assegure o correto funcionamento do sistema de seguros, cujo objetivo maior é, como antes mencionado, garantir ao segurado a efetiva reparação dos danos sofridos mesmo em caso de insolvência (ou mero inadimplemento) do agente segurador. Sob esse ponto de vista, não seria razoável que se exigisse, da parte prejudicada, a busca de uma declaração judicial de invalidade do negócio, tendo-se como válidos os negócios em que tal declaração não fosse obtida.

Assim, vislumbramos a nulidade do contrato, por força do disposto no art. 166 , inc. II, do CCB atualmente vigente ${ }^{23}$, segundo o qual é nulo o negócio jurídico quando foi ilícito seu objeto.

Entendemos que o objeto do contrato é ilícito porque, de acordo com os anteriormente citados artigos 757, par. único, do Código Civil, e 24, do DL 73/66, somente entidades devidamente autorizadas podem atuar como seguradoras, donde conclui-se que, em sendo o contrato firmado por quem não tem autorização legal para operar em seguros privados (e sequer segurador é), possui objeto contrário à lei (seguro tendo como segurador quem não possui autorização para atuar como tal) e, portanto, ilícito.

A lição de Carvalho Santos a respeito do que vem a ser o objeto ilicito parece acolher a tese que aqui se defende, pois o comentatista afirma que a ilicitude "tem por fundamento disposição de lei que, embora infringida, não torna impossivel a formação do ato, mas apenas se limita a não consentir que ele produza efeitos, tal como se verifica na dívida proveniente de jogo." ${ }^{\prime 24}$

Quanto ao segurado, é inegável que age de boa-fé, iludido por uma proposta aparentemente legal, pois nenhuma pessoa, em que pese o valor inferior ao preço dos demais seguros existentes no metcado, contrata seguro sabidamente nulo, que não irá gerar a indenização prometida em caso de sinistro.

23 "Art. 166. É nulo o negócio jurídico quardo:

$\cdots$

II - Quando for ilícito, ou impossivel seu objeto;

$\cdots$

V- Quando a lei taxativamente o declarar nulo ou the negat efeito."

${ }^{24}$ Código Civil Brasileiro Interpretado, $11^{2}$ ed. Rio de Janeiro: Freitas Bastos, 1980, vol. HI, pág. 237. 
E o princípio da boa-fé, no caso, boa-fé objetiva (o que pode se entender, segundo Judith Martins-Costa, como sendo "modelo de conduta social, arquétipo ou standard jurídico", segundo o qual "cada pessoa deve ajustar a própria conduta a este arquétipo, obrando como obratia um homem reto: com honestidade, lealdade, probidade"25; ou, segundo Jorge Mosset Iturraspe, como sendo a espécie que "expresa la lealtad, honestidad, probidady confianza en el comportamiento ${ }^{326}$; ou ainda, no que se refere aos contratos, como sendo a pauta de conduta negocial a ser obedecida pelos contratantes), está consagrado nas cláusulas gerais de boa-fé contidas nos artigos $4^{\circ}$, inc. III, do Código de Defesa do Consumidor ${ }^{27}$ e 422 do $\mathrm{CCB}^{28}$ e, especificamente em relação ao seguro, no art. 765 do $\mathrm{CCB}$ de $2002 .^{29}$

Assim, com base nos ditames do Código Civil e do Código do Consumidor, poderse-ia invocar o princípio da boa-fé objetiva, que pautou a conduta do segurado, mas não foi obedecido pelo pretenso agente ou representante do segurador, a fim de preservar certos efeitos do negócio jurídico através da aplicação, ao caso vertente, do instituto da redução, previsto no art. 170 do $\mathrm{CCB}^{30}$, o que viria em benefício do interesse particular do segurado.

Todavia, em primeiro lugar, diante dos próprios termos do art. 170 , entendemos que não seria caso de ređução, uma vez que a lei refere o fim que as partes teriam querido, caso houvessem previsto a nulidade, o que implicaria na hipótese de que ambos contratantes estivessem agindo de boa-fé, hipótese que não se verifica no caso em comento.

Além disso, seria difícil compatibilizar o interesse privado do contratante com o interesse público na preservação do Sistema Nacional de Seguros Privados (especialmente de suas funções de fiscalização e garantia de reparação dos danos sofridos pelos segurados),

${ }^{25}$ A Boa-Fé no Direito Privado, São Paulo: Revista dos Tribunajs, 1999, pág. 411.

26 Interpretacion Economica de los Contratos, Santa Fé: Rubinzal-Culzoni Editores, 1994, pág. 211.

27 "Art. $4^{\circ}$. A Política Nacional das Relaçōes de Consumo tem por objetivo o atendimento das necessidades dos consumidores, o respeito à sua dignidade, saúde e segurança, a proteção de seus interesses econômicos, a melhoria da sua qualidade de vida, bem como a transparência e harmonia das relações de consumo, atendidos os seguintes princípios:

$\cdots$

III - hatmonização dos interesses dos participantes das relações de consumo e compatibilização da proteção do consumidor com a necessidade de desenvolvimento económico e tecnológico, de modo a viabilizar os princípios nos quais se funda a ordem econômica (artigo 170, da Constituição Federal), sempre com base na boa-fé e equilibrio nas relações entre consumidores e fornecedores;"

${ }_{28}$ "Art. 422. Os contratantes são obrigados a guardar, assim na conclusão do contrato, como em sua execução, os princípios de probidade e boa-fé."

3) "Art. 765. O segurado e o segurador são obrigados a guardar, na conclusão e na execução do contrato, a mais estrita boa-fé e veracidade, tanto a respeito do objeto como das circunstâncias e declarações a ele concernentes."

30 "Art. 170. Se, porém, o negócio jurídico nuio contiver os requisitos de outro, subsistrá este quando o firm a que visavam as partes permite supor que o teriam querido, se houvessem previsto a nulidade." 
pois a possibilidade de convalidação de alguns negócios praticados por entes não autorizados a atuar como seguradotes no mercado nacional traria incetteza ao mercado e poderia gerar, inclusive, um incentivo à proliferação dessa espécie de regócio.

Ainda que se entendesse possivel contornar os óbices acima levantados, pensamos que somente haveria a possibilidade de saneamento do contrato caso houvesse efetiva participação do pretenso segurador estrangeiro na contratação, ou seja, fosse ele efetivamente representado pelo agente que firmou o contrato. Em tal hipótese, encontrarímos na jurisprudência a aplicação, a casos semelhantes, da teoria da aparência de direito, podendo se responsabilizar contratualmente tanto o segurador quanto o suposto agente.

Exemplificando, tem-se o posicionamento adorado pela $3^{a}$ Turma do STJ no julgamento do Recurso Especial n ${ }^{\circ} 56.199 / \mathrm{GO}^{34}$, decisão a qual, embora não tenha envolvido empresa estrangeira, responsabiliza o Banco do Brasill, que não tem autorização para atuar como Sociedade Seguradora, a indenizar segurado, em tazão de constar o nome da instituição financeira como expedidorá do certificado de seguro e recebedora das prestações. Em tal hipótese, porém, como se verifica da leitura atenta do acórdão, havia seguro regularmente contrarado com Sociedades Seguradoras autorizadas legalmente a comercializar seguros privados no país.

Do voto do Min. Relator, Dr. Waldemar Zveiter, bem se percebe que a situação tratada no acórdão é distinta da que se abotda no presente artigo, uma véz que a operação de seguro era legal, havendo intervenção de Sociedades Seguradoras autorizadas, tendo apenas faltado a ciência clata de tal dado no contrato, pelo que o mesmo foi reputado válido e o Banco do Brasil parte legitima para responder pelas obrigações contratadas. ${ }^{32}$

3: "PROCESSUAL E COMERCIAL - CONTRATO DE SEGURO - ILEGTTMIDADE AD CAUSAM DESCARACTERIZADA - MATERIA DE PROVA

I. A ilegitimidade ad causam não se caracteriza quando dos cle-mentos conctetos do contrato de seguro, dos fatos e provas emergil o titular que deve assumir o pólo passivo da ação. II. Matéria de fato năo se reexamina em Especial (Sńmula 07/STJ). MI. Recurso não-conhecido." (Recurso Especial $0^{\circ} 56.199 /$ CO - (Reg. 94/00327404) - Relator: Ministro WALDLMAR ZVEITIER; Reconvinte: Banco do Brasil S/ A; Recorrido: Dalva Sabina Pasquotto Saltes e Outros; Advogados: Drs. Paulo Cesar Calleri e Outros e Gesner Jose Le Senechal Horta e Outro)

32 "Nos Embatgos à Execução decretou-se a carência da ação (art. 267, VI, do CPC) para de-mandar o Banco do Brasil S/A a pagar indenização contratante de apólice de seguro às demandadas, ora recorridas. Todavia, a ilegitimidade do estabelecimento bancário foi afastada pelo aresto recorrido, nestes termos (Als. 81/82);

Nos autos de embargos, o Banco do Brasil $S / A$ argúi, em prelimi-nat, ilegitimidade ad causam. Justifica sua atuação no agenciamento de clientes para formação de seguros em grupo, enfatizando que sua cortetora 'BB Corretora de Seguros e Administradora de Bens' firmou o contato como inter mediária de uma das seguintes Companhias de Seguros: Sul Amética Seguros, Minas Brasil Internacional de Segraros e Seguradora Brasilei-ra-Iraquiana. Pois bem. As $1 \mathrm{~s} .15$ e 14 da Ação de Exxecução (processo em apenso), estão inseridas as duas apólices em que figura como segurado Jorge Assad Salles e emitente o Banco do Brasil $\mathrm{S} / \mathrm{A}$. Também, às fls. 15 e 16, vè-se duas correspondêtacias encaminha das ao segurado, demonstrando a posição de seu seguro, pela BB Corretora de Seguros, 
Na hipótese que ora se estuda, porém, o pseudo-agente, que afirma ser representante contratual do segurador posto no contrato como garantidor do tisco, não o é. Não há aqui contrato de seguro, pelo que não se pode imputar ao segurador teferido no contrato responsabilidade por situação que desconhece e, dessa forma, sequer poderia coibir.

Portanto, volrando ao caso sob análise, quem pode ser responsabilizado é o signatário do contrato nulo. E esse, ao fazer falsa afirmativa de que representava a seguradora posta no contrato como garantidora do risco, bem como, ao afirmar que essa tinha autorização para operar no metcado de segutos brasileíro, o que não se verifica, praticou ato ilícito, não apenas do ponto de vista da lei civil como também da lei penal (o que não se pretende abordar no presente artigo, onde se busca tratar da responsabilização civil do signatário do contrato, em busca da indenização do segurado).

como se ele próprio fosse o segurador. Dessarte, há de se convir que o contrato de seguro foi feito inquestionavelmente pelo Banco do Brasil S/A ou BB Corretora de Seguros.

Não há nos autos nenhum documento ou cópia de correspondên-cia do Banco do Brasil endereçada ao segurado Jorge Assad Salles, comunicando-he o nome da Companhia de Seguros a que foi repas-sado o seguro em grupo, para cumprimento da obrigação avençada. ĺ, pois, responsável no pólo passivo da execução da apólice de seguro o Banco do Brasil S/A, que expediu certificado individual (Apó-lice $n^{\circ}$ 5.901) de Seguro de Vida em Grupo (doc. fls. 13 e 14) e rece-beu do segundo nomalmente as contraprestações. Prevalece, por-tanto, o conceito jurídico de que a cada direito corresponde uma obrigação. Irrelevante o argumento de que o Banco do Brasil S/A não tem a carteira de seguradora. $O$ que importa é que agindo como tal con-tratu a obrigação contratual, o que dá ao credor o direito à ação. Houvesse mais clareza e responsabilidade contratual pelo Banco do Brasil, ao vender o prêmioseguro a Jorge Assad Salles, indicando o nome e a documentação da Companhia a que tenha repassado a obrigação, os beneficiários teriam proposto a ação contra quem de direito.

Poderia, ainda, o Banco do Brasil S/A, ao opot os Embargos, ofe-recer tais documentos; entretanto, perdeu-se com evasivas. Ademais, poderia, ainda se quisesse, dar maior transparência em seus compromissos assumidos, promover a denunciação da lide à Cia. Seguradora que, na função de corretora de seguros, segundo afrma, tenha repas-sado a obrigąção secundária.

A jurisprudência, en casos que tais, admite a denunciação à lide, in verbis:

'É procedente a denunciação da lide à Cia. Seguradora em se tra-tando do seguro facultativo de responsabilidade civil por força de ser a mesma obrigada regressivamente' (TJSP Ac. unânime da 6 Câmara de 12.09.74, in O Proc. Civil à Luz da Jurisprudência. rol. 01, pág. 475, de ALEXANDRE DE PAUL.A.)."

De ver-se, pois, pelo contexto do aresto, que a soluçảo jurídica da lide teve como base fática os elementos concretos apresentados no processo, emergindo do contrato e dos fatos a legitimidade do Banco para figurar no pólo passivo do pedido proveniente do contrato de seguro avençado com os recorridos. Assim, os documentos e instrumentos do negócio jurídico de que se cuida não arastam a obrigatoriedade do recorrente, nem este logrou comprovar sua posição de simples intermediador ou corretor.

Enfim, o aresto apresenta-se escotreito nà orientação que adotou para o desfecho da demanda." (in Marensi, Volaire Giavarina O Seguro no Direito Brasileiro: excertos doutrinários, jurisprudência comentada, legislação, $3^{2}$ ed. Porto Alegre: Sintese, 1996. págs. 256/259) 
Sendo assim, responsabilidade contratual, decorrente de avença securitária, não haveria, mas sim responsabilidade extracontratual, decorrente do ato ilicito praticado, encontrando fundamento para providência na busca de ressarcimento nos arts. 186 e 927 do Código Civil Brasileiro. ${ }^{33}$

Examinada a situação em tela à luz da lição de Pontes de Miranda, citada por J. M. de Carvalho Santos, segundo a qual, para que o ato gere responsabilidade extracontratual, deve ser imputável ao réu, danoso e ilícito, fica patente a existência de responsabilidade extracontratual do firmatário do contrato, que alega agir em nome do segurador, ${ }^{34}$

Existe un ato ou omissão daquele que firma o contrato na posição de representante do segurador, qual seja, a apresentação de proposta e assinatura de contrato nulo como se legal fosse; tal atitude, por óbvio, é imputável a quem assiná o contrato de próprio punho; o ato é danoso, pois priva o segurado do recebimento da indenização em caso de sinistro; o ato é ilícito, pois o contrato é assinado, na condição de segurador, por pessoa à qual a lei brasileira não reconhece tal condição.

Sustentamos ainda que, além do falso agente ou representante do segurador, o corretor de seguros que intermediou o negócio pode ser responsabilizado. Nos termos do disposto no art. 122, do DL. 73/66, é ele o intermediário au torizado a angariar e promover os contraros entre seguradores e segurados..$^{35}$ Ainda, segundo o art. 126, do DL 73/66, o corretor de seguros responde civilmente perante os segurados por culpa ou dolo. ${ }^{36}$

E no ato praticado pelo corretor negligente ou doloso, ao promover a assinatura do contrato nulo, cujo risco é teoricamente repassado a empresá sem autorização para atuar como seguradora no Brasil (e se o risco é repassado ao exterior, necessária seria a intervenção do IRB), encontramos os mesmos elementos geradores da responsabilidade extracontratual antes mencionados, motivo pelo qual parece clara a possibilidade de o segurado prejudicado buscar tessarcimento tanto junto ao falso agente do segurador quanto em relação ao corretor. de seguros que intermediou o negócio, em caso de não tecebimento da indenização contratada para os casos de sinistro.

33 "Art. 186. Aquele que, por ação ou omissăo voluntária, negligência, ou imprudència, violar direito e causar dano a outrem, aioda que exclusivamente moral, comete ato ilicito."

"Att. 927. Aquele que, por ato ilicito (arts. 186 e 187), causar dano a outrem, fica obrigado a repará-lo."

34 "São elementos para que o ato gere a responsabilidade extracontratual: a) un ato ou omissão; b) imputável ao réu, salvo casos excepcionais de reparação sem imputabilidade; c) danoso, por perda ou privação de ganho; d) ilícito.". (Código Civil Brasileiro Interpretado, $11^{2}$ ed. Rio de Janeiro: Freitas Bastos, 1980, vol. III, pág. 318\}

35 "Art. 122. O corretor de seguros pessoa fisica ou jurídica, é o intermediário legalmente autorizado a angariar e promover contratos de seguro entre as Sociedades Seguradoras e as pessoas fisicas ou jurídicas de Direito Privado."

36 "Art. 126. O corretor de seguros responderá civilmente perante os segurados e as Sociedades Seguradoras pelos prejuizos que causar, por omissào, impericia ou negligência no exercicio da profissão." 


\section{VIII - DA POSSIBILIDADE DE ENQUADRAMENTO DAS CONDUTAS DO SUPOSTO AGENTE OU REPRESENTANTE DO SEGURADOR E DO CORRETOR DE SEGUROS NAS HIPÓTESES PREVISTAS NO CÓDIGO DE DEFESA DO CONSUMIDOR}

Diante do disposto nos atts. $2^{\circ}$, caput, e $3^{\circ}$, caput e $\$ 2^{\circ}$, do CDC $\left(\operatorname{Lein}{ }^{\circ} 8.078 / 90\right)^{37}$, o primeiro definindo consumidor e o segundo definindo fornecedor e apontando o seguro entre os serviços por ele prestados, se poderia pensar que todas as operações de seguro caracterizam relações de consumo e, como tal, estão submetidas aos ditames do microsistema de defesa dos direitos do consumidor, como sugerem os adeptos da teoria maximalista, para os quais o CDC seria o diploma legal aplicável a todo o mercado de consumo nacional, protegendo tanto os consumidores não-profissionais como os profissionais.

Todavia, não é esta a opinião dominante na doutrina nacional. Segundo os adeptos da teoria finalista, que se opõe à maximalista, entre os quais se destacam Antonio Herman V. Benjamin, Eros Roberto Grau e Cláudia Lima Marques ${ }^{38}$, com os quais concordamos, somente serão relações de consumo os contratos de seguro onde o destinatário final do serviço (o segurado) seja efetivamente seu destinatário fático e econômico.

Naqueles contratos onde o destinatário do serviço dele se utilizar como insumo, não haverá relâção de consumo. Exemplificando, uma empresa de transportc de valores não é consumidota em um contrato de seguro firmado para garantir o patrimônio de terceiros por ela transportado em sua atividade diária.

Nossos tribunais, embora não de forma unânime, vêm seguindo a teoria finalista, interpretando restritivamente 0 art. $2^{\circ}$ do CDC $^{39}$

37 "Art. 2". Consumidor é toda a pessoa física ou jurídica que adquire ou utiliza produto ou serviço como destinatário final."

"Art. 3". Fornecedor é toda pesson física ou jutídica, pública ou privada nacional ou estrangeira, bem como os entes despersonalizados, que desenvolvem atividades de produção, montagen, criação, construção, transformação, importação, exportação, distribuição ou cotnercialização de produtos ou prestação de serviços.

$\$ 2^{\circ}$. Serviço é qualquer atividade fornecida no mercado de consuno, mediante remuneraçào, inclusive as de natureza bancária, financeira, de crédito e securitária, salvo as decorrentes das relações de caráter trabalhista."

38 "O destinatatio final é o Endverbraucher, o consumidor final, o que retita o bem do mercado ao adquirir ou simplemente utilizá-lo (destinatário final fático), aquele que coloca um fim na cadeia de produção (destinatáxio final econômico) e näo aquele que utiliza o bem para continuar a produzir, pois cle nä́o é a consumidor final, ele está transformando o bem, utilizando o bem para oferecê-lo por sua vez ao seu cliente, seu consumidor". (Contratos no Código de Defeșa do Consumidor: o novo regime das relaçôes contratuats. $3^{2}$ ed. Säo Paulo: Revista dos Tribunais, 1992, pág. 150). 
Feita a necessária ressalva e analisadas, a partir daí, especificamente as relações negociais estabelecidas tendo como contratante um consumidor, igualmente poder-se-ia responsabilizar o suposto agente ou representante do segurador que firma o contrato (e até o próprio corretor de seguros através do qual a contratação é efetuada) por recusa de cumprimento de oferta, hipótese prevista no art. 35 do CDC (Lei n 8.078/90), na medida em que a oferta anunciada acabará por não ser cumprida. 40 .

Todavia, somos da opinião que, neste caso, caberia ao consumidor que teve recusado o cumprimento da oferta, escolher tão somente entre as opções previstas nos incisos II (aceitar outro produto ou prestação de serviço equivalente) e III (rescindir o contrato, com direito à restituição de quantia eventualmente antecipada, monetariamenre atualizada, e a perdas e danos) do teferido artigo 35 , uma vez que, não tendo aquele que se aptesenta como agente ou representante do segurador autorização pata contratar seguros no Brasil, não podetá ser forçado a cumprir a obrigação nos termos da oferta, que era de contrato de seguro.

\section{IX-CONCLUSÃO}

A partir das observações acima lançadas, entendemos que o contrato de seguro firmado por suposto agente ou representante contratual de segurador que não está autorizado a atuar no mercado de seguros nacional é nulo e, como tal, não pode ensejar discussões a respeito de eventual responsabilidade contratual de indenizar o segurado em caso de ocorrência de sinistro.

3) "SEGURO - ACÃO DE COBRANÇA CUMULADA COM PERDAS E DANOS - JULGAMENTO ANTECIPADO DA LIDE - IMPROCEDENCCA DO PEDIDO - RECURSO DA SIEGURADA CONTRATO DE ADESÃO - INAPLICABILIDADE DAS NORMAS DO CDC-INTERPRETAÇO DAS CLÁUSULAS DO CONTRATO - DISTINÇÃO ENTRE FURTO IZ ROUBO - INDIENIZAÇAO DEVIDA - PROCIEDTNCIA PARCIAL, DA DIEMANDA - PROVMENTO DO RECURSO - 1. Inaplicável ao contrato de seguro as disposiçōes do Código de Defesa do Consumidor (Lei $n^{\circ} 8.078 /$ 90), quando a segurada, na qualidade de fonecedora de serviços de contabilidade, năo se caracteriza como consumidora (destinatária final dos serviços), nos termos do art. $2^{\circ}$ da lei de tegência. 2. Como típico contrato de adesão, as cláusulas do contrato de seguro devem ser interpretadas en favor do segurado. 3. Para o segurado, como teigo, o furto e o roubo são expressões que se equivalem, e ocorricto o furto qualificado, com a subtração de bens do estabelecimento prestador de serviços, é devida a indenização pela seguradora, inclusive pelo princípio da boa-fé, inafastável das relações jurídicas securitárias. 4. Recurso provido para julgar parcialmente procedente a denanda." (TAPR AC 0121458-B - (11131) - $5^{2}$ C.Civ. - Rel Juiza Denise Artuda - DjpR 15.09.2000, in Júris Sintese Millenium, Porto Alegre: Sintese, jan/fev/2004)

4il "Art. 35. Se o fornecedor de produtos ou serviços recusar cumprimento à oferta, apresentação ou publicidade, o consumidor poderá, alternativamente e à slia livre escolha:

I - exigir o cumprimento forçado da obrigação, nos temos da oferta, apresentação ou publicidade; II - aceitar outro produto ou prestação de serviço equivalente;

III - rescindir o contrato, com direito à restitujçăo de quantia eventualmente antecipada, monetariamente atualizada, e a perdas e danos." 
Diante de tal cenário, sustentamos que o caminho natural do contratante que, de boa-fé, assina tal espécie de contrato, na busca da defesa de seus interesses, é o ajuizamento de ação ordinária de indenização por ato ilícito contra a pessoa, física ou jurídica, que firma o contrato na condição de segurador ou representante contratual desse.

Da mesma forma, o corretor de seguros que participa do negócio deve ser responsabilizado, pois é de sua atuação, na condição de intermediário entre segurador e segurado, que, segundo a lei, parte a oferta do seguro e, havendo negligência no exame do negócio, cabe sua inclusão no pólo passivo de eventual ação ordinária de indenização por ato ilícito.

É evidente que se recomenda àquele que pretende recorrer à via judicial para tentar. obter indenização pelos prejuizos sofridos que, por medida de economia, antes de ingressar en juizo, promova ampla investigação tcferente à cventual existência de patrimônio de propriedade dos responsáveis, capaz de garantir a indenização pleiteada, ou pelo menos parte dela. Tal medida mostra-se salutar, pois evitaria o ajuizamento de ação que, embora venha a ser julgada procedente, não resulte, na prática, na reparação dos prejuízos.

Pot outro lado, para colaborar com o aperfeiçoamento do Sistema Nacional de Seguros Privados e para rornar mais eficiente a fiscalização de seu correto funcionamento, o que pode evitar a ocorrência de novas fraudes semelhantes, deve ainda o prejudicado denunciar o falso representante contratual do segurador e o corretor que intermediou o contrato à SUSEP, para que o órgão estatal tome as medidas punitivas aplicáveis à espécie, sem prejuízo da cventual comunicação à autoridade policial e ao Ministério Público, para que investiguem a prática de ilíciro penal. 


\section{BIBLIOGRAFIA}

ALVIM, Pedro, O Contrato de Seguro, $3^{4}$ ed. Rio de Janeiro: Forense, 1999.

BEVILAQUA, Clóvis, Direito das Obrigações, Campinas: Red Livros, 2000.

BULGARELLI, Waldírio, Contratos Mercantis, $10^{2}$ ed. São Paulo: Atlas, 1998.

CARVALHO SANTOS, J. M. de, Código Civil Brasileiro Interpretado, $11^{\text {a }}$ ed. Rio de Janeiro: Freitas Bastos, 1980.

GHERSI, Carlos Alberto, Contratos civiles y comerciales, $4^{\mathrm{a}}$ ed. Buenos Aires: Astrea, 1999.

ITURRASTE, Jorge Mosset, Interpretacion Economica de los Contratos, Santa Fé: RubinzalCulzoni Editores, 1994.

MARTINS, Marcelo Guerra, Lesão Contratual no Direito Brasileiro, Rio de Janeiro: Renovar, 2001.

MARENSI, Voltaire Giavatina, OSeguro no Direito Brasileiro: excertos doutrinários, jurisprudência comentada, legislação, $3^{2}$ ed. Porto Alegre: Síntese, 1996.

MARQUES, Cláudia Lima, Contratos no Código de Defesa do Consumidor: o novo regime das relaçôes contratuais. São Paulo: Revista dos Tribunais, 1992.

MARTINS-COSTA, Judith, A Boa-Fé no Direito Privado, São Paulo: Revista dos Tribunais, 1999.

NEGRÃO, Theotonio, e GOUVÊA, José Roberto Ferreira, Código Civil: elegislação civil em vigor, $23^{2}$ ed. São Paulo: Saraiva, 2004.

NERY JR., Nelson e ANDRADE NERY, Rosa Maria de, Novo Código Civil, e Legisla̧̧ão Extravagante Anotados, São Paulo: Revista dos Tribunais, 2002.

PINTO, Carlos Alberto da Mota, Teoria Geral do Direito Civil, $3^{2}$ ed. Coimbra: Coimbra Editora, 1999.

PONTESDE MIRANDA, Francisco Cavalcanti, Tratado de Direito Prizado: direito das obrigações, $2^{2}$ ed. Rio de Janeiro: Borsoi, 1964.

ROPPO, Enzo, O Contrato (Tradução de Ana Coimbra e M. Januário C. Gomes), Coimbra: Livraria Almedina, 1988.

VENOSA, Sívio de Salvo, Direito Civil, $4^{\mathrm{a}}$ ed. São Paulo: Atlas, 2004. 